\title{
Commentary Corticosteroids for community-acquired pneumonia: time to act!
} Djillali Annane ${ }^{1}$ and $\mathrm{G}$ Umberto Meduri ${ }^{2}$

\author{
1Service de réanimation, hôpital Raymond Poincaré (AP-HP), Université de Versailles SQY (UniverSud Paris), 104 boulevard Raymond Poincaré, \\ 92380 Garches, France \\ 2University of Tennessee Health Science Center and Memphis Veterans Affairs Medical Center, Division of Pulmonary, Critical Care, and Sleep \\ Medicine, 956 Court Avenue, Room H316, Memphis, TN 38163, USA
}

Corresponding author: Djillali Annane, djillali.annane@rpc.aphp.fr

Published: 14 July 2008

This article is online at http://ccforum.com/content/12/4/166

(c) 2008 BioMed Central Ltd

See related research by Salluh et al., http://ccforum.com/content/12/3/R76

Critical Care 2008, 12:166 (doi:10.1186/cc6940)

See related research by Saluh et al. http://ccforum.com/content/12/3/R76

\begin{abstract}
The use of corticosteroids for the treatment of community-acquired pneumonia has been reported for almost 50 years. A recent systematic analysis of the relevant literature suggested that corticosteroids reduce the critical illness associated with communityacquired pneumonia. There is little doubt that a prolonged administration of a moderate dose of corticosteroids may alleviate the systemic inflammatory response and subsequent organ dysfunction in severe infection. Whether these favorable effects on morbidity may translate into better survival and quality of life needs to be addressed in additional adequately powered randomized controlled trials.
\end{abstract}

In the previous issue of Critical Care, Salluh and colleagues [1] suggested evidence-based recommendations for corticosteroid therapy in community-acquired pneumonia. Corticosteroids have been used as an adjunct therapy for severe infection for roughly half a century. Contrasting with the clinical practice, researchers are continuing to argue the pros and cons of this therapeutic approach [2].

\section{What is the basis for corticosteroids in community-acquired pneumonia?}

In the era of powerful antibiotics, the likelihood of uncontrolled infection and bacterial proliferation has become less significant. Thus, uncontrolled and overwhelming systemic inflammation is likely the main pathogenetic culprit for progression to organ failure and death in infected patients, such as those with community-acquired pneumonia [3]. Several decades of research on host response to stress have characterized the critical role of an intact hypothalamicpituitary-adrenal response (that is, appropriate tissue levels of corticosteroids) to prevent dissemination of pro-inflammatory storm from one organ to another following local infection [4]. Unsurprisingly, in community-acquired pneumonia, a blunted hypothalamic-pituitary-adrenal axis was clearly associated with the worsening of patient condition [5-7]. More broadly, the concept of critical illness-related corticosteroid insufficiency, defined as inadequate intracellular glucocorticoid antiinflammatory activity for the severity of the patient's illness, has become readily accepted by endocrinologists and intensivists [8]. Ample evidence has shown that prolonged treatment with a moderate dose of corticosteroids can improve intracellular downregulation of inflammatory cytokine transcription and accelerate the resolution of critical illness [8]. New advances in our understanding of the molecular mechanisms of corticosteroid action and its implications for sepsis were recently reviewed [8]. In addition, the recent literature has provided strong experimental support for the use of prolonged corticosteroid treatment in pneumonia [9].

\section{What is the clinical benefit from corticosteroids in community-acquired pneumonia?}

In the previous issue of Critical Care, Salluh and colleagues [1] reviewed four studies investigating corticosteroid treatment in community-acquired pneumonia, including three randomized controlled trials and one retrospective study. Increased survival was reported in two studies investigating treatment duration equal to or greater than 7 days, and lack of survival benefit was reported with short duration of treatment. The authors found evidence for a rather favorable benefit-risk profile with improvement in physiological and clinical outcomes and no evidence for increased harm. The use of corticosteroid treatment in sepsis dates back to the early 1950s [10], and in 1956, favorable effects of hydrocortisone $(80 \mathrm{mg} /$ day orally) were reported in patients with pneumococcal pneumonia [11]. In addition to the above studies, subgroup analyses for patients with community-acquired pneumonia were recently provided from two randomized trials 
investigating prolonged corticosteroid treatment in patients with septic shock and acute respiratory distress syndrome (ARDS) [12]. In septic shock, 101 of 300 patients had community-acquired pneumonia; corticosteroid-treated patients $(n=47)$ had improved survival with a hazard ratio of 0.55 (95\% confidence interval 0.32 to 0.95). In the ARDS trial, 25 of 91 patients had severe community-acquired pneumonia; treated patients had a non-statistically significant increase in the rate of extubation by day 7 (61\% versus $14 \% ; P=0.07)$ and reductions in the median duration of mechanical ventilation ( 5 versus 10 days; $P=0.13$ ), in C-reactive protein levels in plasma $(2.5 \pm 1.8$ versus $12.1 \pm 8.1 \mathrm{mg} / \mathrm{L}$; $P=0.06)$, and in hospital mortality $(16.5 \%$ versus $42.5 \%$; $P=0.3)$ [11]. It is also important to remember that prolonged corticosteroid treatment has already been proven effective in decreasing mortality in two forms of life-threatening pneumonia: Pneumocystis jiroveci pneumonia [13] and severe acute respiratory syndrome [14].

\section{What is the potential harm from corticosteroids in community-acquired pneumonia?}

In theory, corticosteroids may favor the onset of gastroduodenal bleeding, superinfection, metabolic disorders, and muscle weakness. A recent systematic review on the use of corticosteroids for severe sepsis and septic shock, however, failed to show any evidence for an increased risk of bleeding, superinfection, or neuromuscular weakness, whereas hypernatremia and hyperglycaemia occurred more frequently in treated patients (D. Annane, personal communication). It is important for physicians to implement preventive measures and to perform daily screening for possible complications. A specific surveillance of potential sites of superinfection and control of blood glucose and serum sodium levels should be systematically performed.

\section{Which action should be taken now?}

For clinical practice, the favorable benefit-risk profile of a moderate dose of corticosteroids reasonably supports its use in the most severe cases of community-acquired pneumonia with high predicted mortality (that is, patients with shock, respiratory failure, or those with progression of organ dysfunction despite receiving appropriate antibiotics). Most conclusive answers and recommendations, however, can be obtained only with additional research. Pneumonia is the leading cause of sepsis-associated death in the world, with little reduction in mortality achieved over the last 50 years [15]. It is the responsibility of our scientific community and government agencies to promptly set up a large international randomized controlled trial to definitely characterize the benefits and the potential harm of corticosteroids when given to patients with community-acquired pneumonia. A public consensus among experts on the design of future randomized trials will facilitate the progress of this important research.

\section{Competing interests}

The authors declare that they have no competing interests.

\section{References}

1. Salluh JIF, Póvoa P, Soares M, Castro-Faria-Neto HC, Bozza FA, Bozza PT: The role of corticosteroids in severe communityacquired pneumonia: a systematic review. Crit Care 2008, 12: R76.

2. Annane D: Corticosteroids for sepsis: controversial forever? J Crit Care 2007, 22:329-330.

3. Kellum JA, Kong L, Fink MP, Weissfeld LA, Yealy DM, Pinsky MR, Fine J, Krichevsky A, Delude RL, Angus DC; GenIMS Investigators: Understanding the inflammatory cytokine response in pneumonia and sepsis: results of the Genetic and Inflammatory Markers of Sepsis (GenIMS) Study. Arch Intern Med 2007, 167:1655-1663.

4. Chrousos GP: Stressors, stress, and neuroendocrine integration of the adaptive response. The 1997 Hans Selye Memorial Lecture. Ann N Y Acad Sci 1998, 851:311-335.

5. Salluh JI, Verdeal JC, Mello GW, Araújo LV, Martins GA, de Sousa Santino M, Soares M: Cortisol levels in patients with severe community-acquired pneumonia. Intensive Care Med 2006, 32: 595-598.

6. Christ-Crain M, Stolz D, Jutla S, Couppis O, Müller C, Bingisser R, Schuetz P, Tamm M, Edwards R, Müller B, Grossman AB: Free and total cortisol levels as predictors of severity and outcome in community-acquired pneumonia. Am J Respir Crit Care Med 2007, 176:913-920.

7. Gotoh S, Nishimura N, Takahashi O, Shiratsuka H, Horinouchi H, Ono $\mathrm{H}$, Uchiyama N, Chohnabayashi N: Adrenal function in patients with community-acquired pneumonia. Adrenal function in patients with community-acquired pneumonia. Eur Respir J 2008, 31:1268-1273.

8. Marik PE, Pastores SM, Annane D, Meduri GU, Arlt W, Sprung CL, Keh D, Briegel J, Beishuizen A, Dimopoulou I, Tsagarakis S, Singer M, Chrousos GP, Zaloga G, Bokhari F, Vogeser M: Clinical practice guidelines for the diagnosis and management of corticosteroid insufficiency in critical illness: recommendations of an international task force. Crit Care Med 2008, 36: 1937-1949.

9. Li Y, Cui X, Li X, Solomon SB, Danner RL, Banks SM, Fitz Y, Annane D, Natanson C, Eichacker PQ: Risk of death does not alter the efficacy of hydrocortisone therapy in a mouse $E$. coli pneumonia model: risk and corticosteroids in sepsis. Intensive Care Med 2008, 34:568-577.

10. Meduri GU: An historical review of glucocorticoid treatment in sepsis. Disease pathophysiology and the design of treatment investigation. Sepsis 1999, 3:21-38.

11. Wagner HN, Bennett IL, Lasagna L, Cluff LE, Rosenthal MB, Mirick GS: The effect of hydrocortisone upon the course of pneumococcal pneumonia treated with penicillin. Bull Johns Hopkins Hosp 1956, 98:197-215.

12. Annane D, Meduri GU, Marik PE: Critical illness related corticosteroid insufficiency and community-acquired pneumonia: back to the future. Eur Respir J 2008, 31:1150-1152.

13. Briel M, Bucher HC, Boscacci R, Furrer $\mathrm{H}$ : Adjunctive corticosteroids for Pneumocystis jiroveci pneumonia in patients with HIV-infection. Cochrane Database Syst Rev 2006, 3: CD006150.

14. Chen RC, Tang XP, Tan SY, Liang BL, Wan ZY, Fang JQ, Zhong $\mathrm{N}$ : Treatment of severe acute respiratory syndrome with glucosteroids: the Guangzhou experience. Chest 2006, 129: 1441-1452.

15. Mizgerd JP: Lung infection-a public health priority. PLoS Med 2006, 3:e76. 